\title{
Study on Diversity of Pummelo (Citrus grandis Osbeck.) based on Core Quantitative Characters in West Bengal
}

\author{
P. Nandi ${ }^{1}$, R. Swamy Sekhar ${ }^{2}$ and S. Kundu ${ }^{2}$ \\ ${ }^{1}$ Department of Horticulture, Rabindra Nath Tagore Agriculture College, \\ Baijandih, Deoghar-814157, Jharkhand, India \\ ${ }^{2}$ Department of Fruits and Orchard Management, Bidhan Chandra Krishi Viswavidyalaya, \\ Mohanpur-741252, Nadia, West Bengal, India \\ *Corresponding author
}

\section{Keywords}

Pummelo,

Genotypes,

Quantitative

characters,

Variability, TSS

\section{Article Info}

Accepted:

10 September 2019

Available Online:

10 October 2019
The study on diversity of pummelo (Citrus grandis Osbeck) was undertaken to assess the variability of collected genotypes from fourteen district of West Bengal in the year of 2016-17. One hundred twenty four genotypes were selected based on assessment of traits provided by the farmers (fruit bearing frequency, maturity, fruit yield) as well as in-situ observation of trees and fruit's characters with an objective for selecting genotypes from divergent clusters and utilizing them in a hybridization programme is likely to produce desirable segregates in subsequent generations that may lead to desirable improvement in pummelo for quality traits. The analytical works were conducted in the laboratory of Fruits Science of Bidhan Chandra Krishi Viswavidyalaya, Mohanpur, Nadia, West Bengal. The data obtained were analyzed by different method like- Hierarchical cluster analysis, descriptive analysis, Principal Component Analysis and Biplot. The genotypes were grouped based on ten core quantitative characters of fruits into fifty six clusters. It is observed that all the clusters were distant each other and among them cluster 49 was the largest one consisting of 55 pummelo genotypes followed by cluster 43 and cluster 52 with three genotypes. The co-efficient of variation was high $(>20)$ for five measured or quantitative characters like fruit weight, fruit rind thickness, seed weight, acidity, and ascorbic acid. Principal component analysis of ten core quantitative characters of pummelo showed four components with cumulative variance of 69.357 per cent. Highly loaded characters $(>0.5)$, obtained from PCA for quantitative variables in the first two components, were fruit weight, fruit diameter, fruit length, rind thickness, seed number and seed weight. So, considering all the characters it may be concluded that NPC2, NDC5, NPC12, HWC3, NPC11, PRC4, HGC1, NDC4, NPC1, BKC12, NPC10, HWC5, PMC1, $\mathrm{CBC} 8, \mathrm{BKC} 8, \mathrm{BWC7}, \mathrm{NPC} 12, \mathrm{PRC} 7$ etc. can be utilized in genotype selection or crop improvement programme. 


\section{Introduction}

Pummelo (Citrus grandis Osbeck), a tropical fruit plant species, major monoembryonic species of citrus, originated from South East Asia and itis also called as shaddock (Uzun and Yesiloglu, 2012). Pummelo is easily grown in inferior, marginal and backyard orchard. It is considered as an excellent tree for waste land development in arid and semiarid region. Pummelo fruit is a fat, sodium and cholesterol free. This makes pummelo a very good source for dieters. It is a good source of vitamin $\mathrm{C}$ and calories. Besides its use as a table fruit, the fruit and other parts of pummelo plant can also be exploited for different purposes. Its therapeutic and nutritive values along with its taste and flavour have placed it in the regular dietary list of the people living in advanced countries (Mukhopadhyay, 2004).

In spite of tremendous potentiality for commercial exploitation, pummelo plants are yet to be given due importance in India. An urgent need for pummelo conservation is necessary as there is a tendency of declining varietal diversity due to loss of natural habitat. Therefore, the problem of decreasing variability in pummelo needs a particular attention in preventing further loss of plant species that has not been fully uncovered (Wen et al., 2010). No standard variety of pummelo is found in India except Nagpur Chakotra (Rajput and Haribabu, 2004). However, the diverse eco-geographical distribution in India and the occurrence of spontaneous mutation and natural hybridization have given rise to a wide range of variability in citrus. In West Bengal, diverse populations of pummelo also exist in the different agro-ecological zones with a lot of variations in plant and fruit characters. There is direct need for conservation of crop. Variation and selection are the two fundamental aspects of any plant improvement programme. Characterization of citrus genetic resources was first attempted by Bonavia (1890), who described the citrus germplasm available in India. In India many good quality pummelo are available in home gardens and descriptive orchards. Characterization of pummelo using morphological traits will help in selecting genetically potential genotypes for their cultivation, marketing and their use in plant breeding programmes. Few attempts on genetic diversity of pummelo have been done earlier (Chomchalow et al., 1987; Phan et al., 2002; Liu et al., 2006 a). Very few works have been done in India including West Bengal (Murthy et al., 1989; Maiti et al., 2001). Thus, considering the above facts it has been decided to undertake this research programme entitled "Study on diversity of pummelo (Citrus grandis Osbeck.) based on core quantitative characters in West Bengal”.

\section{Materials and Methods}

The study of pummelo diversity was conducted at fourteen districts of West Bengal during 2016-17. The different pummelo districts in which survey was conducted for identification of superior genotypes were North 24 Parganas (NPC), Nadia (NDC), Burdwan (BWC), Purulia(PRC), Hooghly (HGC), Bankura (BKC), South 24 Parganas (SPC), Birbhum (BBC), Howrah (HWC), Murshidabad (MDC), Malda (MLC), Paschim Medinipur (PMC), Uttar Dinajpur (UDC) and Cooch behar (CBC). The diversity was observed mostly in home gardens. The analytical works were conducted in the laboratory of Fruits Science of Bidhan Chandra Krishi Viswavidyalaya, Mohanpur, Nadia, West Bengal. To know the pummelo diversity available in the different districts, primary information was collected from the Sub divisional and District Horticulture Office, Horticulture Research and Development Farm and Krishi Vigyan Kendra. Accordingly different areas were 
surveyed and first hand information was collected from farmers to identify their preferred phenotypes. Individual plant was selected based on assessment of traits provided by the farmers (fruit bearing frequency, maturity, fruit yield) as well as insitu observation of trees (general health)and fruits (fruit shape, fruit size, peel thickness, pulp colour etc.). One hundred twenty four genotypes were selected covering fourteen districts for studying diversified characters of pummelo. All the plants were more or less uniform age and vigour.

The pummelo collections were named on the basis of above said code used for different districts. Ten core quantitative fruit characters (Fruit weight, Fruit diameter, Fruit length, Rind thickness, Rind thickness, Segment number, Seed weight, Acidity, TSS and Ascorbic acid) from 'citrus descriptor' (IPGRI, 1991) were considered for characterization of these pummelo germplasm. Three fully mature, healthy and disease free fruits from each replication were collected randomly from different direction for recording different observations. The physical and chemical characters of fruits were recorded after thorough washing with tap water to remove adhering impurities. Fruit and seed weight was measured by using electronic (digital) balance whereas fruit rind thickness was measured by slide calliperse.

Total soluble solids content of fruits was determined with the help of a hand refractometer. Acidity and ascorbic acid content of fruit were estimated by following the standard methods (AOAC, 1984).Descriptive statistics were used to describe the basic features of the data in a study for quantitative characters. The data obtained were analysed statistically by Hierarchical cluster analysis following single linkage (nearest neighbourhood) method (Gronau and Moran, 2007). The data obtained were further analysed by the method of Principal Component Analysis and Biplot (Metsalu and Vilo, 2015).

\section{Results and Discussion}

The results of descriptive analysis presented in table 1, clearly revealed a wide range of variability in nine quantitative or measured fruit characters among different pummelo collections.

The co-efficient of variation was high (>20) for five measured or quantitative characters like fruit weight, fruit rind thickness, seed weight, acidity, and ascorbic acid. Again, among nine characters, the co-efficient of variation was higher in seed characters like seed weight (64.0), acidity (66.84) and Ascorbic acid (45.47). Higher co-efficient of variation revealed higher variability which indicated that superior clones can be identified from the existing variation. Singh et al., (2015b) observed much less co-efficient of variation (3.455-17.032) among pummelo clones with higher in peel thickness and 100 seed weight.

Hierarchical cluster analysis following single linkage divided 124 pummelo collections into 56 clusters with allowed distance 2.015 considering ten core quantitative characters. Results (Table 2 and Fig. 1) showed that all the clusters were distant each other and cluster 49 was the largest one consisting of 55 pummelo genotypes followed by cluster 43 and cluster 52 with three genotypes.

On the other hand, cluster 21, cluster 28, cluster 29 , cluster 50 , cluster 51 , cluster 53 , cluster 54 , cluster 55 and cluster 56 consisted of 2 pummelo genotypes in each and remaining clusters comprised of single member or genotype. Liu et al., (2006 b) obtained 6 groups by UPGMA analysis using 33 pummelo cultivars and 29 core characteristics. 
Table.1 Variability study of different quantitative characters of pummel

\begin{tabular}{|c|c|c|c|c|c|}
\hline Characters & Minimum & Maximum & Mean & $\begin{array}{c}\text { Std. } \\
\text { Deviation }\end{array}$ & CV (\%) \\
\hline Fruit weight (g) & 462.50 & 1906.60 & 923.28 & 301.09 & 32.61 \\
\hline Fruit diameter (cm) & 8.03 & 18.23 & 13.39 & 2.00 & 14.96 \\
\hline Fruit length (cm) & 9.90 & 21.30 & 13.86 & 2.39 & 17.25 \\
\hline Rind thickness (cm) & 0.67 & 3.83 & 1.69 & 0.62 & 36.96 \\
\hline Segment number & 10.30 & 18.60 & 14.51 & 1.70 & 11.72 \\
\hline Seed weight (g) & 0.00 & 0.68 & 0.25 & 0.16 & 64.00 \\
\hline Acidity (\%) & 0.32 & 1.63 & 0.98 & 0.66 & 66.84 \\
\hline TSS ('brix) & 6.00 & 11.20 & 8.33 & 0.95 & 11.45 \\
\hline $\begin{array}{c}\text { Ascorbic acid } \\
\text { (mg/100 ml juice) }\end{array}$ & 16.50 & 78.00 & 33.52 & 15.24 & 45.47 \\
\hline
\end{tabular}

Table.2 Clusters of pummelo genotypes based on ten core quantitative characters using single linkage clustering methods on squared Euclidean distance matrix

\begin{tabular}{|c|c|}
\hline Cluster number & Cluster members (Allowed distance $\mathbf{2 . 0 1 5}$ ) \\
\hline $\mathbf{1}$ & NDC1 \\
\hline $\mathbf{2}$ & HGC1 \\
\hline $\mathbf{3}$ & NDC4 \\
\hline $\mathbf{4}$ & NPC13 \\
\hline $\mathbf{5}$ & HWC5 \\
\hline $\mathbf{6}$ & NPC2 \\
\hline $\mathbf{7}$ & HWC1 \\
\hline $\mathbf{8}$ & BKC3 \\
\hline $\mathbf{9}$ & PRC7 \\
\hline $\mathbf{1 0}$ & MDC1 \\
\hline $\mathbf{1 1}$ & NPC10 \\
\hline $\mathbf{1 2}$ & NDC5 \\
\hline $\mathbf{1 3}$ & BKC2 \\
\hline $\mathbf{1 4}$ & BWC1 \\
\hline $\mathbf{1 5}$ & BKC 8 \\
\hline $\mathbf{1 6}$ & NDC7 \\
\hline $\mathbf{1 7}$ & NDC9 \\
\hline $\mathbf{1 8}$ & SPC5 \\
\hline $\mathbf{1 9}$ & PRC4 \\
\hline & \\
\hline
\end{tabular}




\begin{tabular}{|c|c|}
\hline 20 & SPC6 \\
\hline 21 & $\mathrm{BKC} 1, \mathrm{BWC} 2$ \\
\hline 22 & MLC3 \\
\hline 23 & HGC8 \\
\hline 24 & NPC4 \\
\hline 25 & $\mathrm{NDC} 12$ \\
\hline 26 & NPC1 \\
\hline 27 & SPC1 \\
\hline 28 & UDC2, BKC10 \\
\hline 29 & CBC8, BWC5 \\
\hline 30 & MDC4 \\
\hline 31 & BKC9 \\
\hline 32 & NPC8 \\
\hline 33 & UDC1 \\
\hline 34 & BWC13 \\
\hline 35 & HWC2 \\
\hline 36 & BKC13 \\
\hline 37 & $\mathrm{BBC} 3$ \\
\hline 38 & NDC2 \\
\hline 39 & BKC7 \\
\hline 40 & HWC3 \\
\hline 41 & SPC4 \\
\hline 42 & UDC4 \\
\hline 43 & BKC11, HGC4, HWC4 \\
\hline 44 & $\mathrm{CBC} 1$ \\
\hline 45 & PKC4 \\
\hline 46 & MDC2 \\
\hline 47 & NDC3 \\
\hline 48 & BWC6 \\
\hline 49 & $\begin{array}{l}\text { PMC1, BWC8, PMC2, NPC3, BWC15, PRC5, } \\
\text { BKC4, BWC3, NPC15, MLC4, PRC11, HGC7, } \\
\text { PRC10, NDC8, BWC12, BKC6, PRC12, } \\
\text { BWC10, BKC5, BWC9, NPC16, BBC4, HGC2, } \\
\text { HGC3, CBC6, HGC5, NPC6, NDC11, CBC5, } \\
\text { NDC9, CBC2, MLC7, MLC2, MDC3, UDC3, } \\
\text { HWC6, PRC2, PRC1, PMC3, PRC8, PRC6, } \\
\text { CBC10, CBC7, PRC3, NPC5, BWC11, CBC4, } \\
\text { PMC5, BBC6, NPC14, CBC9, MLC6, SPC3, } \\
\text { BBC5, BBC1 }\end{array}$ \\
\hline 50 & NPC12, NPC7 \\
\hline 51 & NDC10, NDC6 \\
\hline 52 & $\mathrm{SPC} 2, \mathrm{CBC} 3, \mathrm{BBC} 2$ \\
\hline 53 & BWC14, BWC7 \\
\hline 54 & BKC12, NPC11 \\
\hline 55 & MLC5, MLC1 \\
\hline 56 & PRC9, BWC4 \\
\hline
\end{tabular}


Fig.1 Dendrogram (by single linkage) of different pummelo genotypes using ten quantitative characters

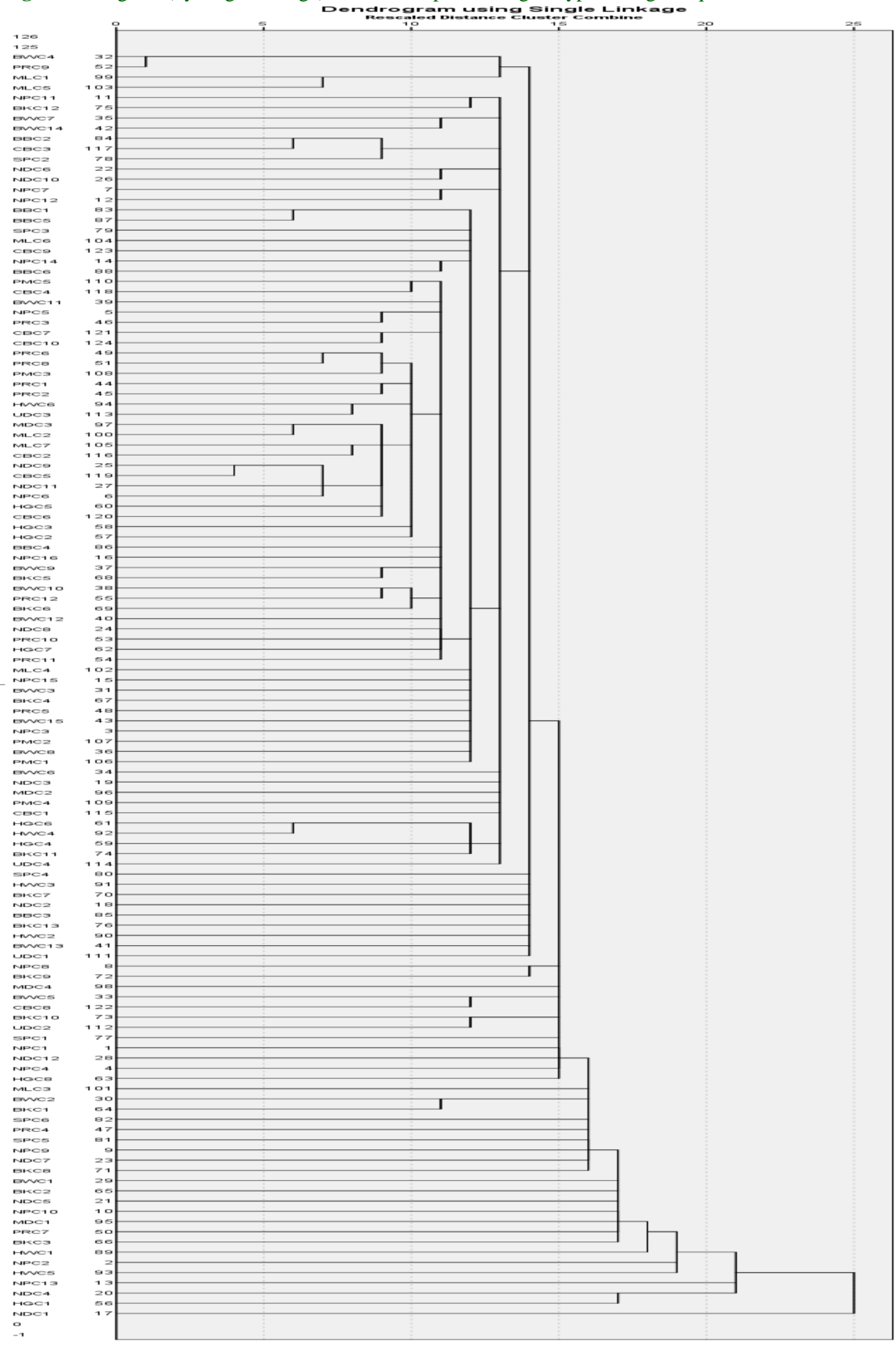


Fig.2 Loading biplot of PCA (F1 Vs F2) for quantitative characters

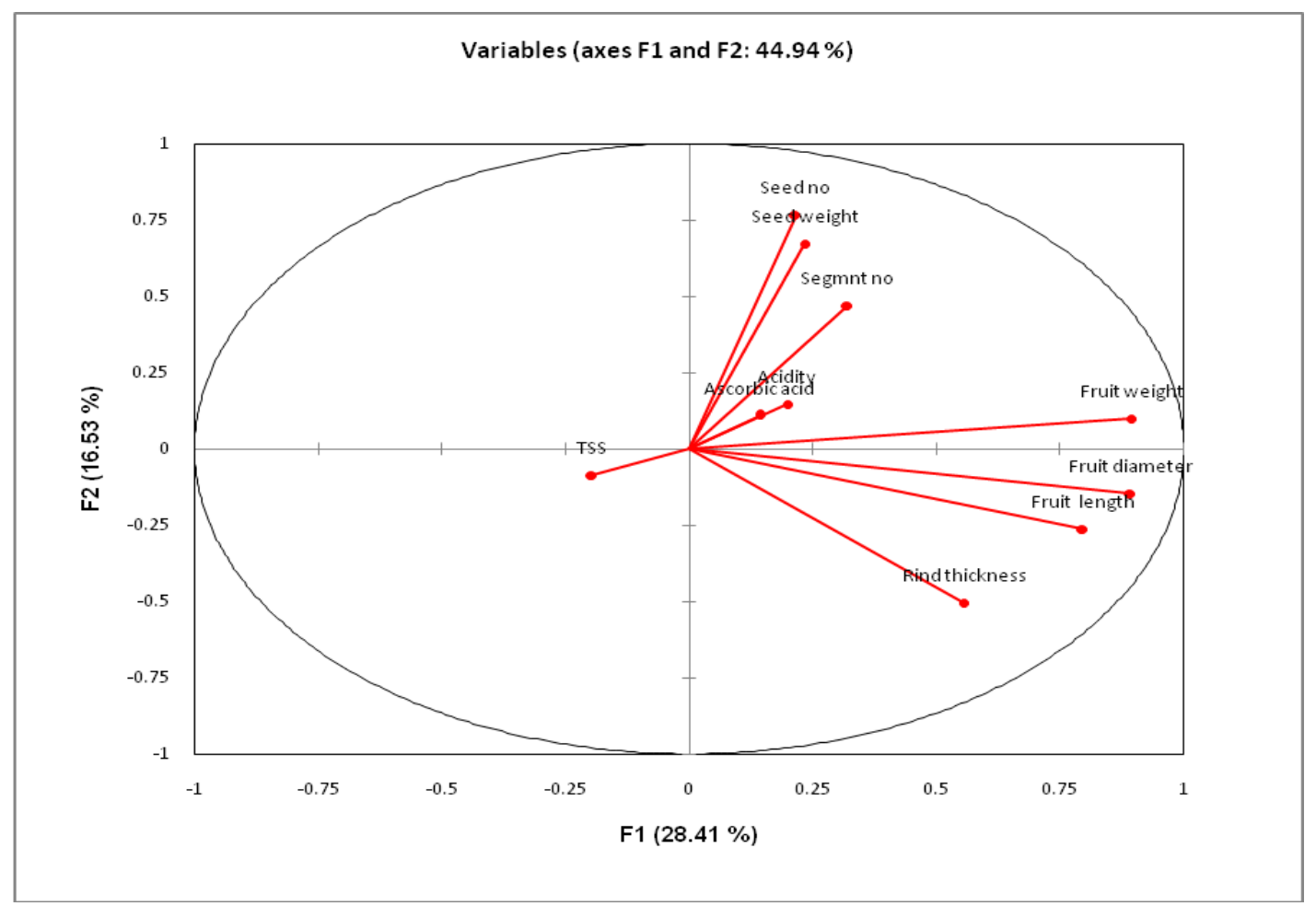

Fig.3 Scoring biplot of PCA (F1 Vs F2) for pummelo genotypes based on quantitative characters

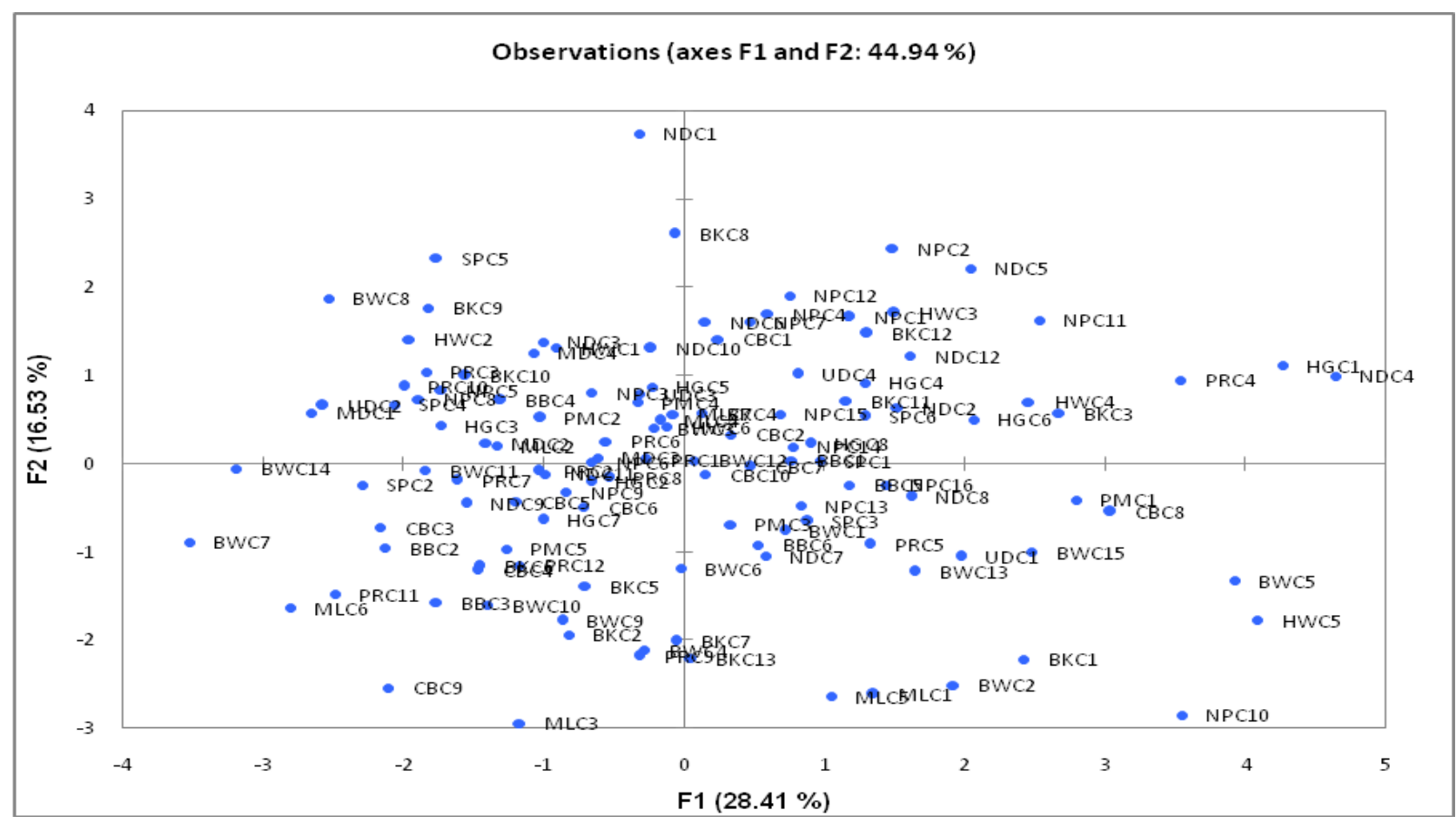


Principal component analysis of ten core quantitative characters of pummelo resulted four components with cumulative variance of 69.357 per cent (Table 3). Components with Eigen value more than 1 were considered only. The Eigen value was high in F1 (2.841) and low in F4 (1.157). The component matrix F1 alone contributed 28.415 per cent of total variance with positive loading of fruit weight (0.894), fruit diameter (0.893), fruit length (0.796), rind thickness (0.556) and acidity (0.199) in contrast to total soluble solids (TSS) which was negatively loaded. The component F2 explained 16.53 per cent of total variance having positively loaded variables of seed number (0.776), seed weight (0.671), segment number (0.469), acidity (0.146) and ascorbic acid (0.109). The negatively loaded variables in this component were rind thickness, fruit length and fruit diameter. The component F3 explained 12.85 per cent of total variance. The highly and positively loaded characters in this component were ascorbic acid (0.734), acidity (0.480), segment number $(0.303)$ in contrast to seed weight and TSS. Component F4 with 11.57 of total variance loaded positively with higher value of TSS (0.708) and acidity (0.614) as compared to segment number which was negatively loaded (Table 3 ).

Loading of ten core quantitative characters and component scores of pummelo genotypes were presented (Fig. 2 and Fig. 3) keeping Xaxis as F1 (component-1) and $\mathrm{Y}$-axis as F2 (component-2). The first and forth quadrants of loading plot were distributed with six and three characters, respectively, where as it was single character in third quadrant (Fig. 2). Similarly, one hundred and twenty four pummelo genotypes were scattered among four quadrants of scoring plot (Fig. 3).

The six characters viz. seed numbers, seed weight, segment number, acidity, ascorbic acid and fruit weight were confined in 1st quadrant of loading plot.
So, the genotypes remained in the 1st quadrant of scoring plot (NPC2, NDC5, NPC12, HWC3, NPC11, PRC4, HGC1, NDC4, NPC1, $\mathrm{BKC} 12$ etc.) had higher mean values for these characters.

Again 4th quadrant of loading plot was confined with three characters viz. fruit diameter, fruit length and rind thickness. Genotypes, corresponding to the 4th quadrant of scoring plot (NPC10, HWC5. BWC5, BKC1, BWC15, PMC1, CBC8, BWC2, UDC1, BWC13, MLC1, MLC5, NDC8, PRC5 etc.), were higher in fruit diameter, fruit length and rind thickness.

Likewise, genotypes present in the 3rd quadrant (MLC3, CBC9, MLC6, BWC7, BWC14, SPC2, CBC3, BBC2, PRC11, BBC3, BWC10, BWC9, BKC2 etc.) were rich in TSS content (Fig. 2 and 3). Singh et al., (2015b) observed almost similar cumulative variance (68.30\%) from first four principal components where acidity, fruit weight, fruit length and fruit width were the most important characters.

The diagram 'Biplot' was used to clarify the relation between genotypes and variables. Results indicated that fruit characters distributed in loading plot contributed a considerable role to the differentiation of pummelo genotypes confined into loading plot.

From the above results, it is concluded that there is a profound diversity among pummelo collections and few genotypes (HGC1, PRC4, NDC4, NDC5, NPC10, HWC5, PMC1, CBC8, BEC5, BKC8, BWC7, NPC12, PRC7 etc.) may be exploited for various attributes based on consumers acceptance as well as few may be important breeding material for development of improved varieties after further evaluation. 


\section{References}

A.O.A.C., 1984, Official Methods of Analysis, 14th Ed. Association Official Agric. Chemist, Washington D.C., pp. 16.

Bonavia, E., 1890, The cultivated oranges and Lemons etc. of India and Ceylon. A.W. Allen and Co., London.

Chomchalow, N., Wunnachit, W. and Lim, M., 1987, Characterization of pummelo in Thailand. Newsletter, IBPG, Regional Committee for Southeast Asia, p. 97.

Gronau, I.; Moran, S., 2007, "Optimal implementations of UPGMA and other common clustering algorithms", Information Processing Letters, 104 (6): 205-210.

IPGRI, 1999, Descriptors for Citrus, International Plant Genetic Resources Institute, Rome, Italy.

Liu, Y., Liu, D.C., Wu, B. and Sun, Z.H., 2006a, Genetic diversity of pummelo (Citrus grandis Osbeck) and its relatives based on simple sequence report markers, Chinese J. Agric. Biotechnol., 3(2): 11926.

Liu, Y., Sun, Z.H., Liu, D.C., Wu, B. and Jiang, D., 2006b, Study on taxonomy of pomelo cultivars. J. Fruit Sci., 23(1): 3540.

Maiti, C.S., Samanta, A.K. and Mitra, S.K., 2001, Genetic variability, heritability and genetic advance relating to some fruit characters in pummelo (Citrus grandis Osbeck.) genotypes, Indian Agric., 45(1/2): 19-23.

Metsalu, T., Vilo, J., 2015, Clustvis: a web tool for visualizing clustering of multivariate data using Principal Component Analysis and heat map. Nucleic Acids Research; 43(1):566-570.

Mukhopadhyay, S., 2004, Taxonomy, chromosomal organization and genetic diversity, In: Citrus production, Postharvest, disease \& Pest Management. Oxford \& IBH Publishing Co. Pvt. Ltd., New Delhi, pp. $1-24$.

Murthy, R.N., Thimmaraju, K.R. and Prasad, T.G., 1989, Physico-chemical characteristics of pummelo types, Environ. Ecol., 7(4): 1033-34.

Phan, T.T.T., Nguyen, P.D. and Nguyen, T.M.A., 2002, Identification of pummel (Citrus grandis Osbeck) cultivars using isozyme electrophoresis, Biologischewetenschappen, 67(1): 13-19.

Rajput, C.B.S. and Haribabu, R.S., 2004, Citriculture, Kalyani Publisher, pp. 10918.

Singh, S.K., Singh, A., Nath, V., Parthasarahy, V.A., Sthapit, B. and Vinoth, S., 2015b, Pummelo in homestead garden: conservation through family farming. Indian J. Plant Genet. Resour., 28(1): 132-38.

Uzun, A. and Yesiloglu, T., 2012, Genetic Diversity in Citrus, In: Genetic Diversity inPlants (Ed. by M. Caliskan). pp. 21331.

Wen, B., Cai, C. Wang, R., Tan, Y. and Lan, Q., 2010, Critical moisture content windows differ for the cryopreservation of pomelo (Citrus grandis) seeds and embryonic axes. Cryo Lett., 31:29-39.

\section{How to cite this article:}

Nandi, P., R. Swamy Sekhar and Kundu, S. 2019. Study on Diversity of Pummelo (Citrus grandis Osbeck.) based on Core Quantitative Characters in West Bengal. Int.J.Curr.Microbiol.App.Sci. 8(10): 1275-1283. doi: https://doi.org/10.20546/ijcmas.2019.810.150 